\title{
ALTERIDADE E PSICANÁLISE: AS MODALIDADES DE OUTRO EM LACAN
}

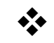 \\ Marcele Homrich Ravasio \\ Instituto Federal Farroupilha - IFFar - Brasil
}

\begin{abstract}
Resumo
O presente texto busca apresentar o conceito de alteridade a partir de um diálogo com a psicanálise, mais especificamente com os conceitos apresentados por J. Lacan. Para tanto, será percorrido um trabalho conceitual entorno das modalidade de Outrem em Lacan: pequeno outro, grande Outro, objeto pequeno a, o outro do laço social e o Heteros. Para finalizar indicamos que a alteridade não é apenas algo que se põe no outro, mas que emerge no sujeito pelo Outro que nos constitui. A possibilidade de reconhecer o outro como alteridade coloca em potência a dimensão dos desconhecimentos que definem o eu.
\end{abstract}

Palavras-chave: Alteridade; psicanálise; Outro; Heteridade;

\section{Introdução}

O conceito de alteridade não tem seu nascimento em Freud, e não se encontra tal discussão na sua obra. Mesmo que Freud tenha acolhido o sofrimento de seus pacientes sem uma formulação prévia, trabalhando com o reconhecimento do outro na sua pura diferença, não encontramos o desenvolvimento do conceito de alteridade em sua obra. Nessa via, o autor, em seu trabalho investigativo, ofereceu guarida à experiência radical com o desconhecido, sem apressar-se em produzir uma categoria prévia, uma nomeação que restituísse respostas às suas perguntas. Assim, a obra freudiana rompeu com o mesmo, e se abriu para o novo, fazendo uso de uma posição que contempla a concepção de alteridade.

Nesse sentido, como um desses momentos do trabalho do autor em uma posição de alteridade, está o texto de 1919, O estranho, que desenvolve a ambivalência e a proximidade entre estranho e familiar, considerando o estranho um matiz do íntimo. A formulação freudiana designa a alteridade como elemento de si, mas também do outro. É interessante indicar que Freud escreveu esse texto durante a Primeira Guerra Mundial, quando estava sendo experimentado um tempo em que os homens viviam momentos de destruição do campo do outro, tentando aniquilar aquilo emerge no outro de si. Nessa via, o autor define o estranho como uma variedade do terrorífico, ou seja, como uma forma de expressão do terror, 
implicando uma certa desorientação. É pontuado por Freud o fato de que tal palavra não encontra designação em todos os idiomas, tratando-se de um sentimento que resiste à nomeação através da linguagem, e assim é precioso o caminho traçado no texto, buscando no conto O Homem da Areia, de Hoffmann, alguma condição de linguagem.

O conto apresenta Natanael como protagonista que se vê às voltas com o Homem de Areia, que é narrado por sua mãe no momento de dormir. O homem jogava areia nos olhos das crianças que não conseguiam mantê-los abertos. Natanael reatualiza tal criatura nas relações do seu cotidiano, porém não percebe tal movimento. Assim, o texto busca apresentar que as condições do olhar estão ancoradas em elementos da composição psíquica, não existindo uma neutralidade quando olhamos. Somos atravessados pelos laços com o Outro/outro.

Freud (1974b) maneja com a palavra em alemão unheimlich (estranho) e sua proximidade em termos com sua antítese, heimlich (familiar), para designar que o estranho é variedade do familiar - o estranho estaria como 'inquietante', em decorrência da marca do recalcamento. "Heimlich é uma palavra cujo significado se desenvolve na direção da ambivalência, até que finalmente coincide com seu oposto, unheimlich. Unheimlich é, de um modo ou de outro, uma subespécie de heimlich" (ibidem, p. 301).

A inquietante estranheza seria sentida pelo sujeito quando ele se depara com algo que não poderia ser reconhecido como seu, uma vez que aquilo deveria ter ficado fora da vista, recalcado, mas aparece como um retorno e se coloca para o sujeito que não consegue vê-lo como seu. O estranho retorna a partir de uma exterioridade, como "algo que é familiar e há muito estabelecido na mente, e que somente se alienou desta através do processo de repressão" (ibidem, p. 301). Nessa direção, aquilo que se coloca como exterioridade constitui o âmago da experiência subjetiva.

Assim, a dicotomia exterioridade-intimidade estaria posta como uma ilusão de descontinuidade; com a inquietante estranheza, o sujeito experimenta uma certa suspensão disso que separa o dentro-fora. Tal diluição dos limites entre dentro e fora, proposto por Freud no artigo de 1919, indica um sujeito atravessado, perpassado pela alteridade.

A alteridade tem seu nascimento na filosofia da diferença, com os pensadores Deleuze, Derrida e Levinas. Neste campo, a discussão é extensa. Segundo Scharinger (2009), a discussão foi introduzida por Heidegger (2005) ao inserir a noção de diferença ontológica, situando a diferença entre ser e ente - o primeiro deve ser valorizado, e o segundo só pode ser entendido em relação ao primeiro. Nessa via, Heidegger criticou a metafísica, ao indicar que havia uma negação acerca da diferença ontológica, acusando, assim, de metafísica da 
identidade, da presença. Ao desenvolver essa crítica sobre a metafísica, o pensador propôs um novo paradigma que produziu o pensamento sobre a diferença.

Na produção de um pensamento divergente, Levinas (1961) produz uma crítica à metafísica como ontologia. Esta compreende a valorização do ser, implicando a valorização do eu, do sujeito e, nesse sentido, do mesmo. Assim, Levinas indica que a relação do Eu com o mundo é uma relação de posse e identificação, um entendimento contra a alteridade. Nesse ponto situa-se o que o autor chamou de posse do Outro, nessa compreensão não existindo independência do Outro. Assim, sustenta sua crítica à ontologia e fundamenta sua compreensão no Outro como pura diferença, que não é passível ao controle e ao domínio, mas existe na sua verdadeira alteridade. Nesse caminho, encontramos os rastros do conceito de alteridade que foi introduzido pela filosofia, e mais tarde tomado por Jacques Lacan, evocando as modalidades de outrem.

\section{Alteridade em Lacan}

Lacan desenvolve diferentes perspectivas para as modalidades de outro, sendo a questão da alteridade percorrida em toda sua obra, apresentando cinco modalidades de outrem: o 'pequeno outro', o semelhante, igual e rival, oriundo do Estágio do Espelho, portanto, do registro imaginário; o 'grande Outro', cujo discurso é o inconsciente, sendo os sintomas, os lapsos, os chistes, os sonhos, correspondendo também ao tecido da linguagem, como registro simbólico; o 'objeto pequeno a', do registro real, causa de desejo, o êxtimo; o 'outro do laço social', no campo do gozo estruturado pelos discursos que constituem os laços sociais, nas posições possíveis de mestre, capitalista, universitário ou histérica; e por fim o 'Outro gozo', Heteros, o gozo feminino, enquanto diferença pura e radical.

O pequeno outro oferece a matriz constitutiva do sujeito. No início desse processo, não existe a primeira pessoa, mas sim um processo de alienação, que é a base da existência psíquica. Esse trabalho psíquico é detalhado por Lacan em vários textos: Complexos familiares na formação do indivíduo (1938), Formulações sobre a causalidade psíquica (1946), e em desenvolvimento mais detalhado no texto Estágio do Espelho como formador da função do Eu (1949).

Ao desenvolver o Estágio do Espelho, Lacan oferece as bases para compreensão da gênese do eu como resultado da identificação com uma imagem ideal que é projetada no outro. Tal processo é desenvolvido em três momentos. O primeiro é uma indiferenciação entre o eu e o outro, e o que é do outro refere-se ao eu; no segundo momento desenvolve-se o 
transitivismo, que rege o eu e o outro, os quais são contornados e delimitados; e, por fim, o movimento em que o sujeito conhece o outro na sua diferença. $\mathrm{O}$ desenrolar desse trabalho psíquico passa de uma relação especular e dual, para então habitar a diferença e a estranheza entre eu e o outro.

As formulações de Lacan sobre o Estágio do Espelho são como um representante do complexo de intrusão, conforme indica Quinet:

\begin{abstract}
Lacan descreve o que ocorre na subjetividade da criança quando nasce um irmão como complexo de intrusão. Ela sente como um intruso que vem apropriar-se do lugar que o pequeno sujeito imagina ocupar no desejo da mãe. Mas o sujeito identifica-se com este outro, o irmão, de modo imaginário, e o outro se torna indissociável do eu e, pior, o eu é indissociável do outro. Essa bipolaridade caracteriza o registro imaginário e constitui a infelicidade do homem, pois o outro, quando não é objeto de desejo, é um estorvo, um inferno. Um eu nunca vem sozinho, ele está sempre acompanhado do outro, seu ideal. Eis por que instância do eu é fundamentalmente paranoica. (2012, p. 10).
\end{abstract}

O outro é passível de ser conhecido e delimitado. Conforme indicam Costa e Moschen (2013, p. 441), implica-se uma possibilidade de nomeação, classificação, catalogação e qualificação, e, "uma vez submetida a essas operações, poderá emergir como um outro isolável e apartado do sujeito [...] implica um estatuto identitário". Esse próximo que é semelhante, no qual amamos e rivalizamos, onde o eu-ideal é encarnado pelo outro-ideal, surge nas relações sociais, nos pares e nos ímpares, sendo o que é do eu aparece no outro.

O Outro é registro simbólico, como marca do sujeito efeito do discurso; grande Outro é o inconsciente, enquanto as determinações simbólicas do sujeito, elementos que o constituem e o posicionam em um determinado lugar singular. A Outra cena, o Outro palco, indica que o sujeito não sabe conscientemente de qual lugar fala, sendo que é regido por marcas e determinações que vieram de fora, por estes outros que lhe deram origem e que vão estar impregnados nesse Outro que habita o sujeito. Portanto o Outro é um discurso que situa o sujeito em uma posição subjetiva, a partir dos significantes que lhe constituem, "[...] onde as cadeias significantes do sujeito se articulam determinando o que o sujeito pensa, fala, sente e age. Nada do sujeito escapa ao Outro: sua mente e seu corpo, seus movimentos e seus atos. Seus sonhos e sua vigília” (QUINET, 2012, p. 22).

O Outro é o 'tesouro dos significantes', onde habita a verdade do sujeito, em que só é possível na forma de um meio-dito, sendo um saber sobre o sujeito que inclui um não saber, marcando a impossibilidade de apreensão completa, marcada pelo engano, pelo equívoco. $\mathrm{Na}$ alteridade do registro simbólico, encontramos o estranho que nos constitui, que marca a 
cultura arraigada no sujeito, a partir das suas marcas primeiras, que se movem e se ressignificam na relação com os significantes. Tendo como marca a polissemia dos significantes, tem caráter móvel e fugidio.

Em termos constitutivos, temos até aqui o pequeno outro, que apresenta como marca o empréstimo identitário que concerne ao processo de subjetivação do sujeito, e que se coloca no cotidiano com os sujeitos que nos relacionamos, em sua possibilidade de descrição e controle. O simbólico, que apresenta o grande Outro como o inconsciente que habita no sujeito, marca a divisão do psiquismo.

O 'objeto $\alpha$ ' apresenta a marca com o primeiro objeto de satisfação, que produz uma ilusão de completude, mas desde sempre é perdido. O objeto $\alpha$, apresentado por Lacan, indica uma falta impossível de ser preenchida, o impossível do Real, mostrando a seu caráter inexequível. Portanto os objetos são sempre revestidos pelo sujeito, mas nunca são 'o objeto' propriamente dito, pois este não existe, é sempre criado, inventado, sempre escapando. Entre sujeito e objeto há uma relação em que a posição de cada um determina a posição do outro. Nas palavras de Costa e Moschen,

\footnotetext{
De um lado temos o sujeito desejante, incompleto, na medida em que é estruturado pelas regras do significante - que não lhe permitem representar a si mesmo, mas apenas emergir no intervalo entre significantes. De outro lado, temos esse objeto causa de desejo que o sujeito recorta do Outro. O objeto $\alpha$ está, ao mesmo tempo, no lado do Outro, enquanto falta na estrutura, e no lado do sujeito como causa de sua existência. (2012, p. 447).
}

Nesse sentido, o que habita no sujeito também habita no outro, algo do Real, que move o desejo. Assim, objeto $\alpha$ estaria nessa impossibilidade de apreensão, de falta de representação, inominável, que coloca em movimento a linguagem, mas que sempre foge dela. Sua emergência pode ser fonte de produção de vida. Nessa perspectiva Quinet indica o objeto $\alpha$ como outro radical, sendo "esse outro que é efetivamente radical, [...] em uma hiância sem representação causando meu desejo e provocando minha angústia” (2001, p. 2).

O objeto pequeno a não se encontra no inconsciente como discurso do Outro, pois não é simbólico, nem significante, mas equivale a uma falta que permite a instalação do inconsciente, sendo um furo simbólico. Ele é marcado pelo seu caráter êxtimo, sendo íntimo e externo ao conjunto de significantes do Outro, tendo um caráter de exterioridade íntima.

Já o outro do laço social se engendra a partir de modalidades já determinadas em nossa sociedade, envolvendo dois sujeitos, sendo um agente de um outro que estão em uma relação dissimétrica, sendo o primeiro dominante e o segundo dominado. Tal lógica compõe o laço 
social, transmitida de geração para geração, garantido a manutenção da sociedade. Contudo esses laços são denominados por Lacan de aparelhos de gozo, promovendo um esvaziamento de gozo ao estabelecer formas de convivência, formando uma canalização, ou ainda um enquadramento do gozo a partir dos laços sociais. Estes laços sociais são nomeados por Lacan, em $\mathrm{O}$ avesso da Psicanálise, como discursos.

É que sem palavras, na verdade, ele (o discurso) pode muito bem subsistir. Subsiste em certas relações fundamentais. Estas, literalmente, não poderiam se manter sem a linguagem. Mediante o instrumento da linguagem instaura-se um certo número de relações estáveis, no interior das quais certamente pode-se inscrever-se algo bem mais amplo, que vai bem mais longe do que as enunciações efetivas. (LACAN, 1969-1970, p. 11).

Os discursos encontram-se para além do campo da fala, tratando-se de um "discurso sem palavras", no qual "não há necessidade de enunciações para que nossa conduta, nossos atos, eventualmente se inscrevam no âmbito de certos enunciados primordiais" (LACAN, 1992, p. 11). Para que o discurso se estabeleça é necessário o ato por parte do agente do discurso, sendo que este, ao ser produzido, imprime uma certa posição ao outro, sustentando a relação entre agente-outro. A cada uma dessas relações possíveis entre agente e outro, Lacan estabelece quatro discursos: discurso do mestre, discurso universitário, discurso da histérica e o discurso do analista. É pertinente indicar que estes discursos não são fixos, e os sujeitos transitam por eles.

Os quatro discursos são apresentados por Lacan através de fórmulas ou matemas, para indicar quatro elementos e quatro lugares, onde se colocam: 'o lugar do agente' que ordena o discurso, onde se pode interpelar ou falar; 'o lugar do outro', sendo a quem o discurso é tomado, cujo efeito que produz no outro, como produto do discurso, é 'o lugar da produção', contudo esta apresenta uma causa que é a verdade, em nome do qual o agente fala, sendo 'o lugar da verdade'. Os elementos que vão transitar nos matemas são S1, o significante-mestre, representando o poder de comando que lhe é próprio; S2, representando o significante de saber, sendo a rede de significantes que se articulam em um saber; \$, significando o sujeito barrado; e o $\alpha$ como objeto pequeno outro, como objeto mais-de-gozar.

Portanto o laço social é articulado a partir dos discursos, e o sujeito que toma o ato ocupa um determinado lugar e produz no outro uma determinada posição, tendo como efeito uma produção, que está articulada com uma determinada verdade. Sendo assim, todo discurso é um aparelho de gozo. Conforme elucida Boudard (2000, p. 64): 
[...] quando tomamos a palavra, ocupamos antes de qualquer coisa, um lugar. Mas qual? Pois existem diferentes lugares de que podemos falar, interpelar o outro, e o efeito do que se dirá aí será diferente em cada um desses lugares. Assim coloca-se em primeiro plano o lugar a partir do qual se toma a palavra: o lugar do agente. Em seguida, trata-se de saber a quem se fala, a que outro se dirige a palavra. [...] Essa palavra endereçada ao outro tem um efeito: é o produto do discurso. Essa produção tem uma outra causa, mais verdadeiramente que o agente do discurso, do qual ele é apenas um semblante. Essa causa motor do discurso é a verdade, em nome da qual fala o agente.

Os discursos, enquanto formas de laços sociais, referem-se às três atividades apresentadas por Freud por seu caráter impossível: governar, educar e psicanalisar. Assim, os discursos correspondem a uma formalização dessas maneiras de relacionamento entre os sujeitos. Lacan (1992) ainda acrescenta dois: o fazer desejar e o fazer comprar. A impossibilidade de fazer desejar e fazer comprar incide na perspectiva de que o poder de um sujeito sobre outro apresenta seus limites, em decorrência do inconsciente que não é passível ao domínio.

O S1 no discurso do mestre é o governante, o senhor, e o S2 o subordinado a esse discurso, estando no lugar de governado e escravo, que através deste pretende obter a produção de objetos para seu uso, caracterizando-se como objetos de gozo. Nessa lógica, há um saber sobre tudo, exigindo do outro que se submeta à lei, porém o que ele produz para usufruto tanto seu quanto do outro é o objeto mais-de-gozar, como fora da lei e fora do saber, representando a impossibilidade na intenção do mestre à sua impostura de ser sabedor de tudo (PEREIRA, 2008).

O discurso do mestre é aquele que coloca o mestre na posição de senhor, daquele que se dirige como mestre ao saber. Coloca-se como todo poderoso, porém não produz o saber, pois quem se coloca no lugar da produção é o escravo. Portanto o senhor é dependente do escravo, e somente através dele obtém o lugar de senhor. O mestre só existe como tal, pois mantém a ilusão de que é autônomo, que tem escravos para lhe servir e que destes pode prescindir. Assim, o mestre pensa que é senhor, sabedor de tudo, enquanto depende do escravo, mas não reconhece a sua dependência (LAJONQUIÈRE, 1999).

No discurso universitário, o autor, a referência, está a serviço do educador, que a partir daí se autoriza para impor seu saber ao outro, fazendo dos estudantes objetos de sua imposição de saber. O resultado é a produção de um aluno subversivo, revoltado, como forma de rejeitar o lugar de objeto, sendo que o aluno irá devolver ao professor algo próprio da verdade da sua lei. A ilusão fundamental é que o aluno não sabe. 
Assim, o discurso universitário tem como dominante o saber que é proferido ao outro posicionado como objeto. Conforme indica Lacan, este discurso se caracteriza por surgir a partir de um giro de um quarto de volta em relação ao discurso do mestre, sendo que o "S2 tem aí o lugar dominante na medida em que foi no lugar da ordem, do mandamento, no lugar propriamente ocupado pelo mestre que surgiu o saber" (1992, p. 97).

Lacan (ibidem, p. 63) indica que no discurso universitário encontramos o mito do Eu ideal, compreendido como Eu que domina, “[...] Eu pelo qual alguma coisa é idêntica a si mesma [...]". Nessa perspectiva assenta-se o discurso pautado na "eu-cracia" - Lacan maneja com o termo democracia, referindo-se à impotência do discurso universitário em exercê-la. $\mathrm{O}$ professor profere seu discurso "no lugar do saber (S2) como agente, ou seja, como porta-voz de conhecimentos enciclopédicos do alto da sua 'eu-cracia', ele faz de seus estudantes objetos de sua imposição de saber" (PEREIRA, 2008, p. 132). Esse discurso é comumente encontrado em instituições clericais e burocráticas, onde quem profere o discurso fala em nome de um saber que não é seu, reduzindo o outro a objeto.

Para Lacan, o discurso que produz o saber é o discurso da histérica, isto é, a verdade do inconsciente que se trata da verdade do desejo, que abriga um saber não sabido, um saber fundamental. $\mathrm{O}$ ato histérico é fazer desejar, o que mostra algo da ordem do cortejar, seduzir, atrair, isso faz laço social. $\mathrm{O}$ ato é sempre histérico quando produz no outro o desejo, inclusive o desejo de saber. $\mathrm{O}$ ato histérico se dirige ao outro como um mestre para estimular seu desejo, autorizando-se do seu gozo para convocar o outro ao lugar de mestre, para que assim produza uma verdade sobre a sua verdade sexual.

$\mathrm{O}$ ato histérico produz no outro o desejo de saber, sendo que o outro é tomado como mestre, até o momento em que sua função de suposto saber seja colocada em questão, necessitando que o outro não saiba demais. Conforme indica Lacan, "a histérica quer que o outro seja um mestre, que saiba muitas e muitas coisas, mas, mesmo assim, que não saiba demais, [...] um mestre sobre o qual ela reine [...] e ele não governe” (1992, p. 122). A histérica obtém, assim, a insatisfação como ponto importante do discurso, e como um subproduto a queixa enquanto registro da impotência.

O discurso do analista tem como marca ser o avesso do discurso do mestre, sendo a posição de não saber, convidando o outro a falar, posicionando-se como objeto $\alpha$, objeto causa de desejo, produzindo que o sujeito fale aquilo que ele sabe, mas desconhece que sabe, sendo este um saber vinculado à verdade do inconsciente. O discurso do analista é o único que considera o outro como sujeito. Conforme indica Almeida (2001, p. 6): 


\begin{abstract}
A estrutura discursiva que define a posição do analista e, como efeito, a do analisante, coloca o analista na posição dominante do agente do discurso, mas como objeto pequeno $\alpha$, ou seja, como objeto perdido, como objeto causa do desejo, que se dirige ao outro enquanto sujeito dividido, separado do significante mestre que o representa. A posição do analista visa, então, a fazer operar no sujeito a produção de seu significante mestre, o qual encontra-se recalcado, ou seja, operar no sujeito um movimento de re-significação da sua castração simbólica, de reposicionamento do significante fálico, primordialmente recalcado. Para que esta operação se torne possível, o analista cala sobre seu próprio desejo, faz silêncio-em-si, segundo a expressão cunhada por J. D. Nasio, e, assumindo uma posição ética discursiva, faz semblante de Sujeito-suposto-saber sobre o desejo do analisante. $\mathrm{O}$ analista não é, portanto, aquele que sabe, não é o sujeito do Saber, ele é o suposto Saber.
\end{abstract}

A característica de cada discurso que envolve o outro no laço social indica o lugar do agente, um lugar de semblante, representando essa função, sendo um elemento que governa, determina e transforma os outros elementos, denominado por Quinet (2012) de 'a dominante'. No discurso do mestre a dominante é a lei, no discurso da histérica é o sintoma, no discurso universitário é o saber, e no discurso do analista é o mais-de-gozar. O outro, em cada uma dessas modalidades de laço social, refere-se ao escravo, sendo o outro do mestre/senhor, no discurso do mestre; o objeto é o outro do saber, no discurso universitário; o outro do sujeito é o mestre e senhor, no discurso da histérica; e o outro do objeto é o sujeito, no discurso do analista. Nessa perspectiva, o discurso do analista é a única modalidade que trata o outro como sujeito.

A modalidade de outrem refere-se ao Outro gozo, apresentado por Lacan para indicar o gozo que se encontra do lado feminino da partilha dos sexos. Segundo Lacan (2003), assim como Um do amor não existe, como a relação sexual, por ser uma dimensão do Real, sendo da ordem do impossível. O Outro gozo tem sua marca no não todo, pás-tout, qualificado como Heteros. Para tanto, Lacan não formulou a partilha dos sexos a partir das condições genitais, mas sim pela função fálica, sendo o gozo fálico masculino, e o gozo Outro sendo feminino. Tais construções são desenvolvidas por Lacan em uma tabela com quantificadores lógicos, signos da lógica matemática.

As fórmulas de sexuação indicam a lógica do Um, onde o constitui Um a partir de um universo fechado, uma totalidade, um todo. No jogo fálico está em jogo uma forma de o sujeito buscar, ilusoriamente, ser Um junto ao seu objeto, apontando para a força, para o poder, a miragem de posse do objeto. Um discurso de plenitude como forma de obturar o real.

Contudo Lacan propõe pensar o feminino a partir do Heteros, em que a mulher não está toda inscrita na lógica fálica, em decorrência de a mulher se sujeitar inteiramente à castração, não existindo para as mulheres um pai originário, não estabelecendo o "ao menos um" que 
escape a castração (ROUDINESCO, 1998). "Já que nenhuma mulher se inscreve fora da castração, já que falta exceção, falta igualmente a regra: não existe clã de mulheres, não há conjunto fechado que atribua uma lei comum desse lado" (ANDRÉ, 1998, p. 221).

Para tanto, a Mulher não existe, sendo que daí as mulheres são um conjunto aberto, e são contadas uma a uma, permanecendo em uma finitude, cada uma se inscreve não toda, na função fálica, tal como colocada pelo significante. O gozo feminino como gozo do Outro é impossível, sem limite. Assim, a indicação lacaniana oferece a ideia de falo como significante, sendo que a mulher não se sujeita totalmente ao Édipo, não havendo um significante para dar conta da condição feminina. Nesse sentido, a relação sexual não existe, não havendo o que faça completude entre as formas de gozo, sendo que são duas, e portanto diferentes e não complementares.

Para haver sexo é necessária a diferença do outro, e nesse sentido a diferença não corresponde às questões biológicas. A lógica do gozo Outro indica as declinações do Heteros como heteronomia, heterodoxia, heterogeneidade e até mesmo heterossexual, sendo definido como aquele que ama as mulheres, assim 'aquele' pode ser homem ou mulher, assim como pode ser de qualquer sexo (em termos genitais) quem está no lugar de 'mulheres'. O que está em questão é que, estando a mulher na lógica do Heteros, o heterossexual é aquele que ama as mulheres, aquele que ama o Outro na sua diferença. O Heteros opõe-se ao poder instituído da lei e das normas ditadas pelo Um do significante da lógica fálica. O Outro, em relação ao instituído, é sempre o diferente. Eis o que caracteriza a Heteridade (QUINET, 2012).

Nessa perspectiva, o Heteros, como gozo Outro, admite a categoria do impossível na medida em que ele não se escreve. A linguagem não o apreende, ele escapa ao significante, e por isso ele também escapa ao laço social, não se deixando prender em um discurso estabelecido. Assim, é a Heteridade que, como reconhecimento da diferença, do Outro gozo, deve estar na base de novos laços sociais. Conforme indica Quinet, existem várias formas de rejeitar a existência do gozo Outro, "[...] como segregar, calar, excluir, inclusive, tentar tornálo igual ao, o mesmo, através do mecanismo de assimilação [...]”. Lacan nos propõe, em Televisão, “deixar a esse Outro seu modo de gozo, eis o que só se poderia fazer não impondo o nosso, não o considerando um subdesenvolvido. (2012, p. 73).

A Heteridade é a condição de abertura à diferença mais radical: diferença de gozo que corresponde à categoria do impossível de ser escrito, de ser previsto, de ser prescrito, sendo que por definição é sempre Outro, tão Outro que é real, verdadeiramente Outro, sendo propriamente a alteridade. 


\section{Considerações Finais}

A alteridade para a psicanálise lacaniana não está posta somente no outro, como aquele que é diferente, mas como sujeito cindido que apresenta a estranheza que habita em si. Conforme indica Figueiredo (1998), a alteridade não se refere a um 'ente-já-constituído', mas, admitindo a existência de uma gênese simultânea da alteridade e do si próprio, aponta que esta é originária do que parecia mais próximo e familiar. Nessa 'alteridade processual', o estranho emerge na mais absoluta proximidade. "Não é a alteridade do outro que surpreende, e eventualmente assusta, mas a surpresa diante de alguém-que-sendo-parte-do-mesmo-é-outro o que constitui o outro na sua alteridade e estrangeirice" (ibidem, p. 47).

Ou seja, a alteridade não é algo que se põe no outro, mas que emerge no sujeito pelo Outro que nos constitui. Reconhecer o outro como alteridade coloca em potência "aquele que traz toda a dimensão dos desconhecimentos que me definem como eu" (KEHL, 2002, p. 21), sendo nele que projeto aquilo que recuso em mim. Assim, escutar o outro requer condições de acolhimento que também indicam a posição frente à alteridade que nos atravessa, como Outro. A escuta e a escrita podem ser formas de acolhimento e reconhecimento acerca do que desconhecemos sobre nós mesmos, que traz a marca do inconsciente que nos constitui, sendo que alteridade se demarca nos processos de escutar e escrever, onde emerge a linguagem como demarcadora do Outro.

Para finalizar e possibilitar aberturas, indicamos a pesquisa e a escrita como formas de reconhecimento das modalidades de 'outrem' que nos constituem. Podemos indicar que este trabalho é possível quando nos interrogamos sobre o lugar e a forma como compreendemos, tendo como máxima o que Freud nos indicou, que o Eu não é o senhor da própria morada, demarcando a existência do inconsciente, na medida em que o Outro/outro é sempre enigma. Assim, alteridade e enigma estão intimamente ligados, nas palavras de Schaffer (2013, p. 526), "Direito e avesso da escrita, visível e invisível, nominável e inominável, familiar e estranho são diversas formas de falarmos do labirinto da escrita, do seu enigma sem oráculos, de sua possibilidade de constituir-se como uma experiência de alteridade possível".

A alteridade, a partir das modalidades de Outrem em Lacan, passa pelo processo de especularidade, mas emerge na constituição do objeto pequeno $\alpha$, e na entrada do Outro como tesouro dos significantes, como campo da linguagem. A posição de perguntar, questionar e tensionar com a própria experiência é exercício de reconhecimento do Outro, sobre o movimento inventivo e elaborativo da linguagem, assim como marca uma posição da pesquisa como enigma. Este não precisa ser descoberto na sua totalidade, sendo a linguagem movida 
pelo inominável e dialeticamente um nominável que desliza. A alteridade na pesquisa presentifica-se na escuta e na escrita como testemunho do estrangeiro que nos constitui.

\title{
ALTERITY AND PSYCHOANALYSIS: THE MODALITIES OF OTHER IN LACAN
}

\begin{abstract}
The present text seeds to present the concept of alterity as a dialogue with psychoanalysis, more specifically with the concepts presented by J. Lacan. For both there will be done a conceptual work surrounding the modes of the Other in Lacan: small other, large Other, small object a, the other social loop and the Heteros. Finally, we indicate that the alterity isn't just something that puts itself on the other, but that emerges in the subject by the Other which constituted us. The possibility to reconginze the other as alterita puts in potential the dimension of unknowns that define the I.
\end{abstract}

Key Words: Alterity, Psychoanalysis. Other. Hereditary.

\section{Referências}

ANDRÉ, S. O que quer uma mulher? Rio de Janeiro: Jorge Zahar Editor, 1998.

FIGUEIREDO, L. C. M. Ética e técnica em psicanálise. São Paulo: Escuta, 2008.

FREUD, Sigmund. O estranho. In: Ed. Standard Brasileira das Obras Completas de Sigmund Freud. Rio de Janeiro: Imago, 1974b. p. 275-304.

HEIDEGGER, M. O ser e o tempo, parte I. Petrópolis: Vozes, 2005.

KEHL, Maria Rita. Sobre ética e psicanálise. São Paulo: Companhia das Letras, 2002.

LACAN, J. Outros escritos. Rio de Janeiro: Jorge Zahar Editor, 2003.

LEVINAS, Emmanuel. Totalidade e infinito. Lisboa: Edições 70, 2000.

PEREIRA, Marcelo Ricardo. A impostura do mestre. Belo Horizonte: Argvmentvm, 2008.

QUINET, Antonio. A heteridade de Lacan. Revista Heteridade, v. 2. 2001. . Os outros em Lacan. Rio de Janeiro: Zahar, 2012.

ROUDINESCO, E.; PLON, M. Dicionário de psicanálise. Rio de Janeiro: Jorge Zahar Editor, 1998. 
SCHARINGER, J. P. Psicanálise e alteridade: um percurso em Lacan pelas diferentes modalidades de outrem. Dissertação (Mestrado em Psicologia Clínica e Cultura) Universidade de Brasília, Brasília, 2009.

SCHAFFER, M. Escrever sobre o escrever. Revista Psicologia e Sociedade, v. 21, edição especial, p. 105-111, 2009.

Escrita e alteridade: um texto em viagem-enigma. Educação e Realidade, Porto Alegre, v. 38, n. 2, p. 521-537, abr./jun. 2013.

Data de recebimento: $30 / 11 / 2016$

Data de aceite: 23/03/2017

\section{Sobre a autora:}

Marcel Homrich Ravasio é psicóloga, especialista em Educação Infantil, Mestre em Educação (UNISINOS), Doutora em Educação (UFRGS). Docente do Mestrado em Educação Profissional em Educação Profissional e Tecnológica do Pólo Instituto Federal Farroupilha. Endereço eletrônico: marcele.ravasio@iffarroupilha.edu.br 